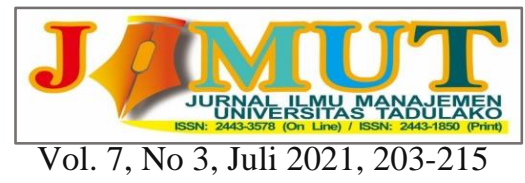

\title{
ANALISISI PENGENDALIAN PERSEDIAAN BAHAN BAKU FERMENTASI BIJI COKELAT PADA RUMAH COKELAT DI KOTA PALU
}

\author{
Hidayatun Nihlah \\ Husein Hi. Moh. Saleh \\ Program Studi S1, Manajemen, Fakultas Ekonomi dan Bisnis, Universitas Tadulako \\ Email: hidayatunnihlah14@gmail.com
}

\begin{abstract}
Abstrack
This research aims to determine the inventory control system for raw materials that must be carried out by Rumah Cokelat in chocolate production. This research used quantitative methods by using Economic Order Quantity (EOQ), Safety Stock and Reorder Point methods. Based on an analysis of the purchase of raw materials, fermentation cocoa beans for optimal chocolate production, according to the Economic Order Quantity (EOQ) method during 2018 at the Rumah Cokelat as much as 3.961,6 kg with a purchase frequency of six times. The quantity received for safety stock in 2018 amounted to 1.729,3 kg, then the number of Reorder Point in 2018 was 1.737,3 kg. From the result of the analysis, it is known that the total inventory cost according to the EOQ method was Rp. 13,732,035.2, while based on company wisdom the total inventory cost was Rp. 17,889,726,2. So that the Rumah Cokelat used the Economic Order Quantity (EOQ) method, it can save inventory costs in the amount of Rp. 4,157,691.
\end{abstract}

\section{Keywords: Inventory Control, Raw Materials, EOQ Method.}

\section{Abstrak}

Penelitian ini bertujuan untuk mengetahui sistem pengendalian persediaan bahan baku yang harus dilakukan oleh Rumah Cokelat dalam produksi cokelat.. Penelitian ini menggunakan metode kuantitatif, dengan menggunakan metode Economic Order Quantity (EOQ), Safety Stock dan Reorder Point. Berdasarkan analisi pembelian bahan baku fermentasi biji cokelat untuk produksi cokelat yang optimal menurut metode Economic Order Quantity (EOQ) selama tahun 2018 di Rumah Cokelat yaitu sebanyak 166,7 kg dengan frekuensi pembelian sebanyak 6 kali. Kuantitas persediaan pengaman atau Safety tock tahun 2018 sebesar $7.586 \mathrm{~kg}$. Untuk jumlah Reorder Point tahun 2018 yaitu $7.594 \mathrm{~kg}$. Dari hasil analisis diketahui total biaya persediaan menurut metode Economic Order Quantity (EOQ) sebesar Rp. 13.732.035,2, sedangkan berdasarkan kebijakan perusahaan total biaya persediaan sebesar Rp. 17.889.726,2. Sehingga jika Rumah Cokelat menggunakan metode Economic Order Quantity (EOQ) dapat menghemat biaya persediaan sebesar Rp. 4.157.691.

\section{Kata Kunci : Pengendalian Persediaan, Bahan Baku, Metode EOQ}




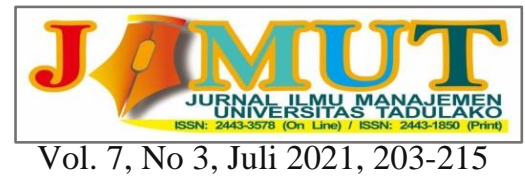

\section{PENDAHULUAN}

Kakao atau Theobroma Cacao L lebih dikenal dalam masyarakat dengan buah cokelat, yang kemudian diolah sehingga menjadi cokelat bubuk. Tanaman kakao berasal dari hutan hujan tropis di Amerika Tengah. Tanaman kakao masuk ke Indonesia sejak tahun 1560, tetapi baru menjadi produk penting pada tahun 1921. Kurang lebih pada tahun 1930-an Indonesia dikenal menjadi Negara pengekspor biji kakao terpenting didunia. Pada tahun 2010 Indonesia menjadi pengekspor biji kakao terbesar ke tiga di dunia dengan produksi biji kering 550.000 ton setelah Negara Pantai Gading 1.242.000 ton dan Gana dengan Produksi 662.000 ton. (Sumber : Ditjenbun)

Sulawesi Tengah adalah salah satu daerah penghasil kakao terbesar di Indonesia. Bahan pembuat cokelat ini merupakan komoditas unggulan petani seluruh Kabupaten di Provinsi Sulawesi Tengah. Produksi kakao petani Sulawesi Tengah setiap tahunnya mencapai 250.000 ton. Salah satu daerah pengahasil kakao terbanyak adalah Kabupaten Parigi Moutong.

Penelitian ini dilakukan untuk mengetahui perencanaan serta pengendalian bahan baku yang optimal dengan metode perhitungan bahan baku yang digunakan adalah Economic Order Quantity (EOQ) sebagai perhitungan persediaan yang optimal. Jenis bahan baku yang dibahas dalam penelitian ini adalah fermentasi biji kakao yang merupakan bahan pokok dalam pembuatan cokelat. Untuk memenuhi kebutuhan persediaannya, Rumah Cokelat memesan biji kakao langsung dari para petani kakao dari Palolo dan Pantai Barat.

Rumah Cokelat adalah salah satu industri manufaktur yang mengolah biji kakao menjadi cokelat yang berlokasi di JL. Setia Budi No.18. Dalam memproduksi cokelat bahan utama yang digunakan adalah fermentasi biji kakao dan lemak kakao.

Berikut merupakan data penggunaan fermentasi biji kakao pada Rumah Cokelat Tahun 2018 :

\begin{tabular}{|c|c|c|}
\hline No. & Bulan & Jumlah (Kg) \\
\hline 1. & Januari & 165 \\
\hline 2. & Februari & 94 \\
\hline 3. & Maret & 240 \\
\hline 4. & April & 240 \\
\hline 5. & Mei & 78 \\
\hline 6. & Juni & 45 \\
\hline 7. & Juli & 273 \\
\hline 8. & Agustus & 205 \\
\hline 9. & September & 371 \\
\hline 10 & Oktober & 10 \\
\hline 11. & November & 25 \\
\hline \multirow[t]{2}{*}{12.} & Desember & 150 \\
\hline & Total & 1.896 \\
\hline
\end{tabular}

\section{KAJIAN LITERATUR}

\section{Pengertian Manajemen Operasi dan Produksi}

Menurut Fahmi (2011:1) Produksi merupakan output yang dihasilkan suatu perusahaan baik dalam bentuk barang (goods) ataupun jasa (service) dalam satu periode waktu yang kemudian akan dihitung sebagai nilai tambah bagi perusahaan. Manajemen operasi merupakan aktivitas untuk mengelolah input melalui sistem transformasi atau pengubahan 
atau transformasi sedemikian rupa sampai menghasilkan suatu output yang dapat berupa barang atau jasa (Yamit, 2003:5).

\section{Pengertian Persediaan}

Manajemen persediaan adalah keahlian perusahaan dalam mengendalikan serta mengelola setiap kebutuhan barang. Baik barang mentah, barang setengah jadi, dan barang jadi agar tetap tersedia baik saat kondisi pasar dalam keadaan normal maupun dalam kondisi naik-turun (Fahmi, 2011:109).

\section{Biaya Persediaan}

Terdapat lima kategori biaya yang dikaitkan dengan keputusan persediaan yaitu (Yamit, 2003:131) :

\section{Biaya Pemesanan}

Biaya pemesanan (order cost) adalah biaya yang dikaitkan dengan usaha untuk mendapatkan bahan baku atau bahan dari luar. Biaya pemesanan dapat berupa: biaya penulisan pemesanan, biaya materai/perangko, biaya faktur, biaya pengetesan, biaya pengawasan, dan biaya transportasi.

2. Biaya Penyimpanan

Unsur terpenting dari biaya simpan (carrying cost) terdiri dari :

a. Biaya modal. Meliputi: opportunity cost, atau biaya modal yang diinvestasikan dalam persediaan, gedung, serta peralatan yang diperlakukan untuk mengadakan dan memelihara persediaan.

b. Biaya Simpan. Meliputi: biaya sewa gudang, perawatan dan perbaikan bangunan, listrik, gaji personel keamanan, pajak atas persediaan, pajak dan asuransi peralatan, biaya perawatan dan perbaikan peralatan. Biaya tersebut ada yang bersifat tetap (fixed), variabel, maupun semi fixed atau semi variabel.

c. Biaya Risiko. Meliputi: biaya keuangan, asuransi persediaan, biaya susut secara fisik, dan risiko kehilangan.

Beberapa komponen biaya penyimpanan persediaan tersebut relatif kecil, namun secara jumlah keseluruhan dari biaya penyimpanan ini sangat besar. Beberapa penelitian memperlihatkan bahwa biaya persediaan berkisar 35\% dari nilai persediaan. Sebagian besar biaya penyimpanan adalah biaya modal atas Opportunity Cost.

3. Biaya Kekurangan Persediaan

Biaya kekurangan persediaan (Stockout) terjadi bila persediaan tidak ada digudang saat diperlukan untuk kegiatan produksi atau saat konsumen memintanya. Biaya yang berhubungan dengan Stockout meliputi : biaya penjualan atau permintaan yang hilang (biaya ini sangat sulit dihitung), biaya yang berhubungan dengan proses pemesanan kembali seperti, biaya ekspedisi khusus, penanganan khusus, biaya penjadwalan kembali produk, biaya penundaan, dan biaya bahan pengganti.

4. Biaya yang Dikaitkan Dengan Kapasitas

Biaya ini timbul disebabkan adanya perubahan dalam kapasitas produksi. Perubahan kapasitas produksi dibutuhkan perusahaan guna mencukupi fluktuasi dalam permintaan. Perubahan kapasitas produksi menyebabkan terjadinya perubahan dalam persediaan. Biaya yang dikaitkan dengan kapasitas meliputi: biaya kerja lembur untuk meningkatkan kapasitas, pelatihan tenaga kerja baru, dan biaya perputaran tenaga kerja (labour turn over cost).

5. Biaya Bahan atau Barang 
Biaya bahan atau barang merupakan harga yang harus dibayar atas item yang dibeli.biaya ini dipengaruhi oleh besarnya diskon yang diberikan oleh supplier. Oleh karena itu biaya bahan atau barang bermanfaat dalam menentukan apakah perusahaan sebaiknya menggunakan harga diskon atau tidak.

\section{Pengertian Pengendalian Persediaan}

Menurut Rangkuti (2007) Pengendalian persediaan/pengawasan persediaan merupakan salah satu fungsi manajemen yang dapat dipecahkan dengan menerapkan metode kuantitatif. Sedangkan menurut Assauri (2005:180) pengendalian persediaan adalah salah satu aktivitas dari rangkaian kegiatan-kegiatan yang saling berhubungan erat satu sama lain dalam seluruh operasi produksi perusahaan sesuai dengan apa yang sudah diagendakan lebih dulu baik waktu, jumlah, kualitas, serta biaya.

\section{Tujuan Pengendalian Persediaan}

Suatu pengendalian persediaan yang dijalankan perusahaan tentu mempunyai tujuantujuan tertentu. Tujuan pengendalian persediaan menurut (Assauri, 2005:185) yaitu :

1. Menjaga agar perusahaan tidak mengalami kehabisan persediaan bahan baku yang berakibat terhentinya proses produksi

2. Menjaga agar persediaan perusahaan tidak terlalu besar, sehingga biaya-biaya yang timbul dari persediaan tidak terlalu besar

3. Menghindari terjadinya pembelian dalam jumlah kecil karena akan berakibat biaya pemesanan menjadi besar.

\section{Metode Dalam Pengendalian Persediaan}

\section{Economic Order Quantity (EOQ)}

Handoko (2014:339) Mengatakan Model Economic Order Quantity (EOQ) digunakan untuk menetapkan kuantitas pesanan persediaan guna meminimalisir biaya langsung penyimpanan persediaan serta biaya kebalikannya (Inverse Cost) pemesanan persediaan.

\section{Safety Stock atau Persediaan Pengaman}

Menurut Fahmi (2011:111) Safety Stock adalah kemampuan perusahaan dalam menciptakan kondisi persediaan yang selalu sama atau penuh pengamanan dengan harapan perusahaan tidak akan pernah mengalami kekurangan persediaan.

\section{Reorder Point}

Reorder Point ialah titik dimana perusahaan atau institusi harus memesan barang atau bahan agar melahirkan kondisi persediaan yang terus terkendali (Fahmi, 2011:111). Reorder Point ialah saat atau titik dimana harus diadakan pesanan lagi sedemikian rupa sehingga kedatangan atau penerimaan material yang dipesan itu datang tepat pada waktu dimana persediaan di atas Safety Stock sama dengan nol (Riyanto, 2010).

\section{METODE PENELITIAN}

\section{Jenis Penelitian}

Jenis penelitian dalam penelitian ini adalah deskriptif kuantitatif. Deskriptif kuantitatif berarti menganalisis, menggambarkan serta meringkas berbagai kondisi dan situasi dari berbagai data dalam bentuk angka yang telah dikumpulkan sebagai hasil dari analisa hasil wawancara dan pengamatan tentang masalah yang terjadi dilapangan (Wiratha, 2006). 
Tujuan dari penelitian deskriptif dalam penelitian ini yaitu untuk mendapatkan gambaran serta keterangan tentang kebijakan dalam pengendalian persediaan bahan baku khususnya fermentasi biji cokelat pada Rumah Cokelat. Penelitian ini berfokus pada fakta-fakta yang diperoleh dari Rumah Cokelat saat penelitian.

\section{Lokasi Penelitian}

Penelitian ini dilakukan di Rumah Cokelat Jl.Setia Budi No.18 Besusu Tengah, Palu Timur, Kota Palu Sulawesi Tengah. Pemilihan tempat ini dikarenakan belum optimalnya persediaan bahan baku khususnya biji cokelat, sehingga membutuhkan kebijakan pengendalian persediaan bahan baku.

\section{Metode Pengumpulan Data}

Penelitian ini dilakukan langsung berkaitan dengan kebijakan pengendalian persediaan bahan baku biji cokelat pada Rumah Cokelat. Pada proses pengumpulan data, digunakan metode cross section, yakni mengambil data pada Rumah Coklat dalam waktu yang telah di tentukan. Dalam hal ini data yang di ambil berupa segala biaya dan jumlah bahan baku yang berkaitan dengan persediaan pada Tahun 2018. Pada proses pengumpulan data yang bersifat primer, peneliti menggunakan tiga cara penelitian, yaitu :

a. Observasi

Obeservasi sebagai metode untuk mengumpulkan data dilakukan dengan mengamati beberapa kegiatan yang sedang berlangsung di lokasi penelitian tehadap bahan baku dan proses produksi yang kemudian dilakukan pencatatan hasil pengamatan. Dalam hal ini observasi dilakukan di Rumah Cokelat.

b. Wawancara

Wawancara merupakan pertemuan antara dua orang guna berbagi informasi melalu tanya jawab. Dalam hal ini wawancara dilakukan pada Manajer Rumah Cokelat mengenai proses produksi serta bahan baku dalam pembuatan cokelat.

c. Dokumentasi

Arikunto (2005) dokumentasi adalah mencari data tentang hal-hal yang berupa catatan, transkip, buku, surat kabar, majalah, notulen rapat, agenda dan sebagainya. Untuk penelitian ini teknik dokumentasi yang digunakan berkaitan dengan penggunaan persediaan bahan baku.

\section{Menentukan Economic Order Quantity (EOQ)}

Menurut Yamit (2003:237) metode Economic Order Quantity (EOQ) digunakan untuk menentukan kuantitas pesanan persediaan yang dapat meminimumkan biaya langsung penyimpanan persediaan dan biaya pemesanan persediaan. Pengertian Economic Order Cuantity (EOQ) sebenarnya merupakan biaya pembeliaan yang paling minimum yang dilakukan tiap kali melakukan pembelian. Notasi yang digunakan dalam persamaan matematik Economic Order Quantity (EOQ) adalah sebagai berikut (Yamit, 2003:237) :

$$
E O Q=\mathrm{Q}^{*}=\sqrt{\frac{2 R S}{C}}
$$

1. Total Biaya Tahunan Minimum (TIC) :

$$
\mathrm{TC}=\left(\frac{\mathrm{R}}{\mathrm{Q} *}\right) S+\left(\frac{\mathrm{Q} *}{2}\right) C
$$

2. Total Biaya Pemesanan Tahunan (TOC) :

$$
\mathrm{TOC}=\left(\frac{\mathrm{R}}{\mathrm{Q}^{*}}\right) S
$$

3. Total Biaya Simpan Tahunan (TCC) : 
$\mathrm{TCC}=\left(\frac{\mathrm{Q} *}{2}\right) C$

4. Frekuensi Pemesanan Optimum/Tahun $\left(\mathrm{F}^{*}\right)$ :

$\mathrm{F}^{*}=\frac{\mathrm{R}}{\mathrm{Q} *}$

5. Jarak Siklus Optimum (T*):

$\mathrm{T}=\frac{\mathrm{Q} *}{\mathrm{R}}$

\section{Menentukan Safety Stock}

Menurut Ristono (2013) Safety Stock atau persediaan pengaman meupakan persediaan yang dilakukan untuk mengantisipasi ketidak pastian permintaan dan penyediaan, apabila persediaan pengaman tidak mampu mengantisipasi ketidak pastian tersebut akan terjadi kekurangan persediaan (Stockout). Dari penjelasan di atas, dapat diartikan bahwa Safety Stock memiliki peranan penting dalam pengendalian persediaan sehingga setiap perusahaan harus memperhitungkannya agar tidak terjadi keterlambatan datangnya bahan baku yang dapat menghambat proses produksi.

Cara menghitung Safety Stock atau persediaan pengaman (Slamet, 2007) :

Safety Stock $=($ Pemakaian maksimum - Persediaan rata-rata $)$ LD

Keterangan :

$\mathrm{LD}=$ Lead Time

\section{Menentukan Reorder Point}

Reorder Point adalah kondisi dimana harus dilakukan pesanan lagi sedemikian rupa sehingga kedatangan atau penerimaan material yang dipesan itu datang tepat pada waktu dimana persediaan diatas Safety Stock sama dengan nol (Riyanto, 2010).

Rumus Reorder Point adalah sebagai berikut :

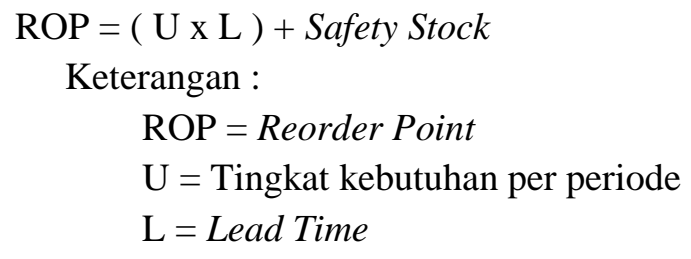

\section{HASIL DAN PEMBAHASAN}

Rumah Cokelat termasuk dalam UPT. Pengembangan Produk Industri Pangan dan Kerajinan Daerah yang berada di bawah naungan Pemerintah. Tetapi dalam menjalankan usahanya khususnya pada pembelian bahan baku yang tidak menggunakan metode apapun dalam menentukan berapa banyak jumlah pembelian yang dilakukan. Rumah Cokelat melakukan pembelian bahan baku hanya berdasarkan data pembelian sebelumnya tanpa menggunakan metode $E O Q$ untuk mengendalikan persedian bahan bakunya. Perbedaan antara jumlah pembelian dan pemakaian bahan baku menyebabkan persediaan bahan baku yang bervariasi setiap bulannya.

Industri Rumah Cokelat melakukan pembelian bahan baku biji cokelat fermentasi untuk memenuhi kebutuhan produksinya. Frekuensi pembelian bahan baku biji cokelat dilakukan setiap bulannya. Rumah Cokelat melakukan pembelian setiap bulan untuk mengantisipasi terjadinya kehabisan bahan baku, keterlambatan dalam pengiriman serta untuk mecegah terjadinya kenaikan harga. Rumah Cokelat melakukan pembelian bahan baku secara kontinu 


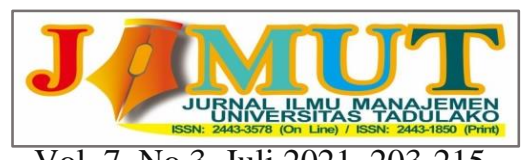

Vol. 7, No 3, Juli 2021, 203-215

berdasarkan pengalaman pada tahun sebelumnya. Berdasarkan Tabel 2 dapat dilihat bahwa banyaknya frekuensi pemesanan yang dilakukan oleh perusahaan sebanyak 12 kali dalam setahun. Sedangkan jumlah pemesanan pada Rumah Cokelat antara 50-300 kg. Pembelian bahan baku biji cokelat pada Tahun 2018 dapat dilihat pada Tabel 2 berikut :

Tabel 2. Frekuensi dan Jumlah Pemesanan Bahan Baku Cokelat Pada Tahun 2018

\begin{tabular}{ccc}
\hline Bulan & Frekuensi Pembelian & Kuantitas Pemesanan $(\mathbf{K g})$ \\
\hline Januari & 1 & 100 \\
Februari & 1 & 250 \\
Maret & 1 & 200 \\
April & 1 & 100 \\
Mei & 1 & 150 \\
Juni & 1 & 150 \\
Juli & 1 & 200 \\
Agustus & 1 & 300 \\
September & 1 & 250 \\
Oktober & 1 & 50 \\
November & 1 & 70 \\
Desember & 1 & 180 \\
Total & 12 & 2.000
\end{tabular}

Sumber : Rumah Cokelat

Dengan menggunakan data dari tabel di atas, dapat dihitung jumlah pembelian rata-rata bahan baku selama tahun 2018 yakni sebagai berikut :

$$
\frac{\text { Jumlah Kebutuhan Bahan Baku }}{\text { Total Frekuensi Pemesanan }}=\frac{2.000}{12}=166,67 \mathrm{Kg}
$$

Dari perhitungan di atas, diperoleh jumlah pembelian rata-rata bahan baku pada Rumah Cokelat Tahun 2018 sebesar 166,67 kg dibulatkan menjadi 166,7 kg.

\section{Biaya Pemesanan}

Biaya Pemesanan merupakan biaya yang dikeluarkan perusahaan akibat adanya pemesanan bahan baku. Komponen biaya pemesanan bahan baku Rumah Cokelat terdiri atas biaya telepon, biaya transportasi, dan biaya bongkar.

1. Biaya Telepon/Internet

Yaitu biaya yang muncul karena adanya pemakaian komunikasi untuk mengadakan bahan baku. Biaya telepon yang dikeluarkan selama tahun 2018 adalah Rp. 14.400.000.

2. Biaya Transportasi dan Upah

Biaya transportasi merupakan biaya yang dikeluarkan perusahaan sebagai biaya perjalanan dari pengepul sampai di Rumah Cokelat. Jumlah biaya transportasi yang dikeluarkan Rumah Cokelat selama Tahun 2018 sebesar Rp. 144.000. Sedangkan upah yang diberikan untuk biaya bongkar adalah Rp. 96.000 .

Tabel 3. Biaya Pemesanan Bahan Baku Cokelat Tahun 2018

\begin{tabular}{|c|c|cc|}
\hline No. & Biaya Satu Tahun & \multicolumn{2}{|c|}{ Rincian } \\
\hline 1. & Biaya Telepon/Internet & Rp. & 14.400 .000 \\
\hline 2. & Biaya Transportasi & Rp. & 144.000 \\
\hline 3. & Biaya Bongkar & Rp. & 98.000 \\
\hline \multicolumn{2}{|c|}{ Total } & Rp. & 14.642 .000 \\
\hline
\end{tabular}




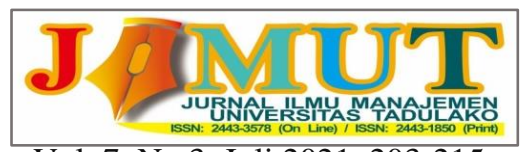

Vol. 7, No 3, Juli 2021, 203-215

Sumber : Rumah Cokelat

Jadi biaya pemesanan bahan baku adalah :

Total Biaya Pemesanan = Rp. 14.642.000

Frekuensi pemesanan 12 kali dalam satu tahun

Biaya Pemesanan $=\frac{\text { Total Biaya Pesan }}{\text { Frekuensi Pemesanan }}$

$$
=\frac{14.642 .000}{12}
$$

$=$ Rp. 1.220.166,67Dibulatkan Rp. 1.220.167

Berdasarkan perhitungan di atas, maka jumlah biaya pemesanan bahan baku yang dilakukan oleh Rumah Cokelat Tahun 2018 adalah Rp. 1.220.167 setiap bulannya.

\section{Biaya Penyimpanan}

Biaya Penyimpanan adalah biaya yang berkaitan dengan penyimpanan bahan baku sebagai stok di gudang. Besar kecilnya biaya penyimpanan dipengaruhi oleh banyaknya jumlah persediaan rata-rata bahan baku. Biaya penyimpanan per periode akan semakin besar jika jumlah persediaan rata-rata bahan baku semakin tinggi. Komponen biaya penyimpanan bahan baku pada Rumah Cokelat sebagai berikut :

1. Biaya listrik dan pendingin ruangan termasuk dalam biaya fasilitas penyimpanan, dimana biaya listrik pada Rumah Cokelat selama satu tahun sebesar Rp. 60.000.000.

2. Biaya Pemeliharaan, meliputi biaya perawatan gudang yang dilakukan oleh pihak Rumah Cokelat setiap bulan. Biaya pemeliharaan per tahun yang dikeluarkan sebesar Rp. 18.000.000. Biaya ini sudah termasuk biaya satpam, biaya untuk membersihkan gudang, biaya penggantian papan sebagai alas untuk menyimpan bahan baku.

Tabel 4. Biaya Penyimpanan Bahan Baku Selama 2018

\begin{tabular}{|c|l|c|}
\hline No. & \multicolumn{1}{|c|}{ Biaya Satu Tahun } & Rincian \\
\hline 1. & Biaya Perawatan Gudang & Rp 18.000 .000 \\
\hline 2. & Biaya Listrik & $\operatorname{Rp} 60.000 .000$ \\
\hline \multicolumn{2}{|c|}{ Total } & $\operatorname{Rp} 78.000 .000$ \\
\hline
\end{tabular}

Sumber : Rumah Cokelat

Jadi biaya penyimpanan bahan baku adalah :

Total biaya penyimpanan $=$ Rp. 78.000.000

Jumlah kebutuhan bahan baku $=2.000 \mathrm{~kg}$

Biaya Penyimpanan $=\frac{\text { Total biaya penyimpanan }}{\text { Total jumlah kebutuhan bahan baku }}$

$$
\begin{aligned}
& =\frac{78.000 .000}{2.000} \\
& =\text { Rp. } 39.000
\end{aligned}
$$

Biaya penyimpanan yang harus dikeluarkan oleh Rumah Cokelat selama Tahun 2018 adalah sebesar Rp. 39.000 setiap bulan.

\section{Total Biaya Persediaan Bahan Baku}

Pengadaan bahan baku dalam kegiatan produksi tidak akan terlepas dengan biaya produksi. Pada Rumah Cokelat jumlah total biaya produksi yang telah dikeluarkan selama tahun 2018 dapat dihitung dengan rumus :

$$
\text { Dimana }: \begin{aligned}
\mathrm{R} & =2.000 \mathrm{~kg} \\
\mathrm{C} & =\mathrm{Rp} .39 .000
\end{aligned}
$$




$$
\begin{aligned}
& \mathrm{S}=\mathrm{Rp} .1 .220 .167 \\
& \mathrm{Q}=166,7 \mathrm{Kg} \\
& \mathrm{TC}=\left(\frac{\mathrm{R}}{\mathrm{Q} *}\right) S+\left(\frac{\mathrm{Q} *}{2}\right) C \\
&=\left(\frac{2.000}{166,7}\right) 1.220 .167+\left(\frac{166,7}{2}\right) 39.000 \\
&=14.639 .076,2+3.250 .650 \\
&=\text { Rp. } 17.889 .726,2
\end{aligned}
$$

Dari hasil perhitungan di atas, di dapatkan jumlah total biaya persediaan bahan baku pada Rumah Cokelat sebanyak Rp. 17.889.726,2.

Analisis Kebutuhan Bahan Baku Menggunakan Metode Economic Order Quantity (EOQ)

\section{Perhitungan Jumlah Pembelian Bahan Baku Optimal}

Pembelian bahan baku yang optimal dapat dihitung dengan menggunakan rumus :

$$
E O Q=\mathrm{Q}^{*}=\sqrt{\frac{2 R S}{C}}
$$

Dimana $: \mathrm{R}=2.000 \mathrm{Kg}$

$$
\begin{aligned}
& \mathrm{C}=\mathrm{Rp} .6 .899 .100 \\
& \mathrm{~S}=\text { Rp. } 6.832 .935,2
\end{aligned}
$$

$$
\begin{aligned}
E O Q=\mathrm{Q}^{*} & =\sqrt{\frac{2 R S}{C}} \\
& =\sqrt{\frac{2 \times 2.000 \times 6.832 .935,2}{6.899 .100}} \\
& =3.961,6 \mathrm{~kg} \quad \text { Dibulatkan menjadi } 3.961,6 \mathrm{~kg}
\end{aligned}
$$

Dengan menggunakan rumus Economic Order Quantity (EOQ) maka diperoleh jumlah pembelian bahan baku biji cokelat yang optimal pada Rumah Cokelat pada Tahun 2018 adalah $3.961,6 \mathrm{~kg}$.

\section{Perhitungan Frekuensi Pembelian Optimal}

Frekuensi pembelian bahan baku yang optimal dapat dihitung dengan menggunakan rumus sebagai berikut :

Dimana : $\mathrm{Q}=353,8 \mathrm{Kg}$

$$
\mathrm{F}^{*}=\frac{\mathrm{R}}{\mathrm{Q}^{*}}
$$

$$
\begin{aligned}
\mathrm{R} & =2.000 \mathrm{Kg} \\
\mathrm{F}^{*} & =\frac{\mathrm{R}}{\mathrm{Q}^{*}} \\
& =\frac{2.000}{353,8} \quad \text { Dibulatkan menjadi } 6 \text { kali }
\end{aligned}
$$

Dengan menggunakan rumus frekuensi pembelian optimal, diperoleh hasil bahwa Rumah Cokelat harus melakukan pembelian bahan baku sebanyak 6 kali dalam satu tahun.

\section{Biaya Pemesanan yang Optimal}

Biaya pemesanan bahan baku yang optimal dapat diketahui dengan menggunakan rumus berikut :

$$
\mathrm{TOC}=\left(\frac{\mathrm{R}}{\mathrm{Q} *}\right) S
$$


Dimana : $\mathrm{R}=2.000 \mathrm{Kg}$

$$
\begin{aligned}
& \mathrm{S}=\mathrm{Rp} .1 \cdot 220 \cdot 167 \\
& \mathrm{Q}=353,8 \mathrm{Kg}
\end{aligned}
$$$$
\mathrm{TOC}=\left(\frac{\mathrm{R}}{\mathrm{Q} *}\right) S
$$$$
=\left(\frac{2.000}{353,8}\right) 1.220 .167
$$

= Rp. 6.832.935,2 Dibulatkan menjadi Rp. 6.832.935,2

Dari perhitungan di atas, diperoleh biaya pemesanan bahan baku yang optimal pada Rumah Cokelat Tahun 2018 sebesar Rp. 6.832.935,2.

\section{Total Biaya Persediaan Bahan Baku Optimal}

Biaya persediaan bahan baku yang optimal dapat dihitung dengan menggunakan rumus berikut :

$$
\mathrm{TC}=\left(\frac{\mathrm{R}}{\mathrm{Q} *}\right) S+\left(\frac{\mathrm{Q} *}{2}\right) C
$$

Dimana $: \mathrm{R}=2.000 \mathrm{Kg}$

$$
\begin{aligned}
\mathrm{C} & =\mathrm{Rp} .39 .000 \\
\mathrm{~S} & =\mathrm{Rp} .1 .220 .167 \\
\mathrm{Q} & =353,8 \mathrm{Kg} \\
\mathrm{TC} & =\left(\frac{\mathrm{R}}{\mathrm{Q} *}\right) S+\left(\frac{\mathrm{Q} *}{2}\right) C \\
& =\left(\frac{2.000}{353,8}\right) 1.220 .167+\left(\frac{353,8}{2}\right) 39.000 \\
& =6.832 .935,2+6.899 .100 \\
& =\text { Rp. } 13.732 .035,2
\end{aligned}
$$

Dengan menggunakan rumus diatas diperoleh jumlah total biaya persediaan bahan baku optimal pada Rumah Cokelat sebesar Rp. 13.732.035,2.

\section{Persediaan Pengaman (Safety Stock)}

Untuk mengihtung jumlah Safety Stock atau persediaan pengaman yang harus dimiliki oleh Rumah Cokelat, dapat dilakukan dengan cara :

$$
\text { Safety Stock }=(\text { Pemakaian maksimum }- \text { Persediaan rata-rata }) \text { LD }
$$

Dimana :

Pemakaian maksimum $=1.896 \mathrm{~kg}$

Persediaan rata $=\frac{2.000}{12}=166,67$ Dibulatkan menjadi 166,7

Lead Time $=1$ hari

Safety Stock $=($ Pemakaian maksimum - Persediaan rata-rata $)$ LD

$$
\begin{aligned}
& =(1.896-166,7) \times 1 \\
& =1.729,3
\end{aligned}
$$

Dari hasil di atas diperoleh jumlah Safety Stock atau pemesanan kembali harus dilakukan oleh Rumah Cokelat saat biji cokelat di gudang sebanyak 1.729,3 kg.

\section{Reorder Point}

Pada Rumah Cokelat lead time atau waktu tunggu bahan baku dari saat dipesan sampai pada saat bahan baku itu datang adalah 1 hari. Maka untuk mengetahui kapan saat yang tepat bagi Rumah Cokelat untuk melakukan pemesanan adalah :

$$
\mathrm{ROP}=(\mathrm{U} x \mathrm{~L})+\text { Safety Stock }
$$


Dimana $: U=\frac{\text { Jumlah pemakaian bahan baku }}{\text { Jumlah hari kerja dalam setahun }}$

$$
=\frac{1896}{240}
$$$$
=7,9 \quad \text { Dibulatkan menjadi } 8 \mathrm{Kg}
$$

$\mathrm{L}=1$ hari

Safety Stock $=1.729,3 \mathrm{~kg}$

$$
\begin{aligned}
\mathrm{ROP} & =(\mathrm{U} \times \mathrm{L})+\text { Safety Stock } \\
& =(8 \times 1)+1.729,3
\end{aligned}
$$$$
=1.737,3 \mathrm{~kg}
$$

Jumlah Reorder Point dengan menggunakan metode Economic Order Quantity (EOQ) adalah sebesar $1.737,3 \mathrm{~kg}$.

\section{Perbandingan Pengendalian Persediaan Antara Kebijakan Perusahaan Dengan Kebijakan Menggunaka Metode Economic Order Quantity (EOQ)}

Untuk mengetahui metode mana yang lebih efektif dalam penyediaan bahan baku, maka diperlukan perbandingan antara penyediaan bahan baku menurut Rumah Cokelat dan penyediaan bahan baku dengan perhitungan menggunakan metode Economic Order Quantity (EOQ). Perbandingannya dapat dilihat pada tabel berikut :

Tabel 5. Perbandingan Persediaan Bahan Baku Antara Kebijakan Perusahaan Dan Dengan Menggunakan Metode EOQ

\begin{tabular}{lcc}
\hline \multicolumn{1}{c}{ Perihal } & Kebijakan perusahaan & Metode EOQ \\
\hline Kuantitas Pembelian & $166,7 \mathrm{~kg}$ & $3.961,6 \mathrm{~kg}$ \\
Frekuensi Pembelian & $12 \mathrm{kali}$ & $6 \mathrm{kali}$ \\
Biaya Pemesanan & Rp. 1.220 .167 & Rp. $6.832 .935,2$ \\
Biaya Penyimpanan & Rp. 3.250 .659 & Rp. 6.899 .100 \\
Safety Stock & - & $1.729,3 \mathrm{~kg}$ \\
Reorder Point & - & $1.737,3 \mathrm{~kg}$ \\
\hline Total Biaya Persediaan & Rp. $17.889 .726,2$ & Rp. $13.732 .035,2$ \\
\hline
\end{tabular}

Sumber : Rumah Cokelat (Data diolah tahun 2019)

Berdasarkan Tabel 4.6 dapat dilihat perbedaan yang cukup besar antar kebijakan yang ada pada Rumah Cokelat dan dengan yang menggunakan metode Economic Order Quantity (EOQ). Selain itu, Economic Order Quantity (EOQ) juga memperkirakan jumlah frekuensi dalam pembelian selama satu tahun dan juga jarak waktu kapan dilakukannya pembelian bahan baku kembali. Dengan diketahuinya jumlah pembelian maka hal ini dapat digunakan sebagai acuan bagi Rumah Cokelat dalam melakukan pengendalian persediaan bahan bakunya.

Dari hasil perbandingan pada Tabel 4.6, kuantitas pembelian bahan baku dengan menggunakan kebijakan Rumah Cokelat sebesar 166,7 kg diperoleh dengan cara membagi jumlah kebutuhan bahan baku selama setahun dengan frekuensi pemesanan sebanyak 12 kali dalam setahun. Jumlah ini lebih kecil bila dibandingkan dengan menggunakan metode Economic Order Quantity (EOQ) yaitu sebanyak 3.961,6kg. Dengan frekuensi pembelian sebanyak 6 kali yang didaptkan dengan cara total pemesanan dibahagi dengan jumlah pembelian bahan baku yang optimal. Biaya pemesanan optimal sebesar Rp. 6.832.935,2 diperoleh dengan cara jumlah pemesanan selama setahun dibahagi dengan jumlah pemakaian optimum lalu dikalikan dengan biaya pemesanan yang ada di Rumah Cokelat. Biaya 


\section{JPMIT \\ Vol. 7, No 3, Juli 2021, 203-215}

pemesanan yang dikeluarkan adalah sebesar Rp. 1.220.167 sehingga diperoleh selisih biaya sebesar Rp. 5.612768,2.

Total biaya persediaan didapatkan dari hasil penjumlahan antara biaya pemesanan dan biaya penyimpanan yang ada di Rumah Cokelat. Untuk total biaya persediaan berdasarkan kebijakan yang ada di Rumah Cokelat diperoleh hasil sebesar Rp. 17.889.726,2. Sedangkan dengan menggunakan metode Economic Order Quantity diperoleh hasil sebesar Rp. 13.732.035,2. Sehingga dengan menetapkan metode ini Rumah Cokelat dapat menghemat biaya sebesar Rp. 4.157.691.

\section{KESIMPULAN DAN SARAN}

\section{Kesimpulan}

Dari hasil perhitungan dan penelitian yang telah dilakukan maka dapat ditarik kesimpulan sebagai berikut :

1. Pengendalian persediaan pada Rumah Cokelat dengan menggunakan metode Economis Order Quantity (EOQ) lebih optimal dibanding kebijakan yang ada di Rumah Cokelat

2. Safety Stock atau persediaan pengaman yang diperlukan Rumah Cokelat dengan menggunakan metode Economis Order Quantity (EOQ) adalah $7.586 \mathrm{~kg}$. Safety Stock ini harus ada di gudang untuk mengantisipasi terjadinya kehabisan atau keterlambatan bahan baku.

3. Jumlah Reorder Point yang diperoleh dengan menggunakan metode Economis Order Quantity (EOQ) sebesar $7.594 \mathrm{~kg}$. Pada saat persediaan mencapai titik ini, Rumah Cokelat harus melakukan pemesanan kembali.

\section{Saran}

Berdasarkan kesimpulan di atas maka peneliti memberikan saran kepada Rumah Cokelat untuk menerapkan metode Economic Order Quantity (EOQ) agar perusahaan dapat mengendalikan persediaan bahan baku cokelat.

\section{REFERENSI}

Assauri, Sofian. 2005. Manajemen Produksi. Penerbit : FE-UI. Jakarta.

Carter dan K. William. 2009. Akuntansi Biaya, Audit, Akuntansi Pajak. Penerbit : Salemba Empat. Jakarta.

Ditjenbun. 2009. Kakao, Statistik Perkebunan, Direktorat Jenderal Perkebunan Jakarta.

Fahmi, Irham. 2012. Manajemen Produksi dan Operas. Penerbit : ALFABETA. Bandung.

Fitra. H, Nur Azmi. Effendy. Howara, Dafina. 2017. "Analisi Manajemen Persediaan Bahan

Baku Cokelat Pada Industri Rapoviaka Simple Di Kota Palu”. Jurnal ISSN 2338-3011.

Handoko dan T. Hani. 2014. Dasar-Dasar Manajemen Produksi dan Operasi. Bagian Pertama. Penerbit : BPFE, Yogyakarta.

Herjanto, Eddy. 2008. Manajemn Operasi. Penerbit : PT. Raja Grasindo Persada. Jakarta.

Heizer, J dan Render, B. 2005. Operation Management. Edisi Ketujuh Buku 2. Penerbit : Salemba Empat. Jakarta.

Ishak, Aulia. 2010. Manajemen Operasi. Edisi Pertama. Penerbit : Graha Ilmu. Yogyakarta.

Kurniawan, Hendra. 2007. Perencanaan dan Pengawasan Produksi. Penerbit : CV. Andi Ofset. Jogyakarta.

Kusuma, Hendra. 2009. Manajemen Produksi. Penerbit : ANDI Yogyakarta. Yogyakarta.

Margaretha, Farah. 2004. Teori dan Aplikasi Manajemen Keuangan, Investasi dan Sumber Dana Jangka Pendek. Penerbit : Grasindo. Jakarta. 


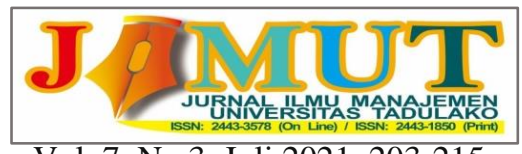

Vol. 7, No 3, Juli 2021, 203-215

Muzayyanah. Suamba, I Ketut. Dewi, Ratna K. 2015. "Analisis Pengendalian Persediaan Bahan Baku Biji Kakao pada Pabrik Delicacao Bali di Kabupaten Tabanan”. Jurnal ISSN 2301-6523 vol. 4 No. 4.

Prasetya dan Lukiastuti. 2011. Manajemen Operasi, Bagian Pertama. Penerbit : CAPS. Yogyakarta.

Rangkuti, Freddy. 2007. Manajemen Persediaan Aplikasi di Bidang Bisnis. Penerbit : PT. Raja Grafindo Persada. Jakarta.

Riduwan. 2009. Skala Pengukuran Variabel- variabel Penelitian. Penerbit : CV Alfabeta. Bandung.

Ristono, Agus. 2009. Manajemen Persediaan Edisi Pertama. Penerbit : CV. Graha Ilmu. Yogyakarta.

Ristono, Agus. 2013. Manajemen Persediaan. Penerbit : CV. Graha Ilmu. Yogyakarta

Riyanto, Bambang. 2010. Dasar-Dasar Pembelanjaan Perusahaan. Penerbit : BPFE. Yogyakarta.

Slamet, Agus. 2007. Penganggaran Perencanaan dan Pengendalian Usaha. Semarang : UPT UNNES Press.

Subagyo, Pangestu. 2000. Manajemen Operasi. Bagian Pertama. Penerbit : BPFE. Yogyakarta.

Tumijo, Roni. Kassa, Saharia. Howara, Dafina. 2015. "Manajemen Persediaan Bahan Baku Pada Industri Kopi "Bumi Mutiara" di Kota Palu". ISSN :2338-3011.

Wahyudi, Rudy. 2015. "Analisis Pengendalian Persediaan Barang Berdasarkan Metode Economic Order Quantity di Toko Era Baru Samarinda". Jurnal ISSN 2355-5408 volume. 2 no. 1.

Wahyuni, Rida. 2015. “Analisis Sisteam Pengendalian Bahan Baku Pabrik Chokato”. Skripsi. Fakultas Pertanian Universitas Andalas, Padang.

Wirartha, I Made. 2006. Metode penelitian Sosial Ekonomi. Penerbit : CV. Andi Offset. Yogyakarta.

Yamit, Zulian. 2003. Manajemen Produksi dan Operasi. Bagian Kedua. Penerbit : Ekonisia. Yokyakarta.

Yamit, Zulian. 2003. Manajemen Kuantitatif Untuk Bisnis (Operasional Research). Penerbit : BPFE-Yogyakarta. Yogyakarta.

https://infosulteng.com/rumah-cokelat diakses pada 25 Mei 2019 pukul 11.15 WITA

http://m.detik.com/finance/industri/d-3073343/kota-palu-punya-rumah-cokelat-ini-fungsinya diakses pada 25 Mei 2019 pukul 11.08 WIB. 